Original Article

\title{
The predictive value of depression in the years after heart transplantation for mortality during long-term follow-up
}

Britta S. Bürker, MD ${ }^{1,2,3}$; Lars Gullestad, MD, PhD ${ }^{1,4,5,6}$; Einar Gude, MD, PhD ${ }^{4}$; Odd E. Havik, $\mathrm{PhD}^{7}$; Anne Relbo Authen, $\mathrm{RN}^{4}$; Ingelin Grov, $\mathrm{RN}^{4}$; Arne K. Andreassen, $\mathrm{MD}, \mathrm{PhD}^{4}$; Arnt E. Fiane, $\mathrm{MD}, \mathrm{PhD}^{1,8}$; Ira R. Haraldsen, $\mathrm{MD}, \mathrm{PhD}^{3}$; Mary Amanda Dew, $\mathrm{PhD}^{9}$; Stein Andersson, $\mathrm{PhD}^{10}$; Ulrik F. Malt, $\mathrm{MD}, \mathrm{PhD}^{1,11}$

${ }^{1}$ Institute of Clinical Medicine, University of Oslo, Oslo, Norway; ${ }^{2}$ Department of Psychiatry of Old Age, Oslo University Hospital - Ullevål, Oslo, Norway; ${ }^{3}$ Department of Psychosomatic Medicine, Oslo University Hospital - Rikshospitalet, Oslo, Norway; ${ }^{4}$ Department of Cardiology, Oslo University Hospital - Rikshospitalet, Oslo, Norway; ${ }^{5}$ K.G. Jebsen Centre for Cardiac Research, University of Oslo, Oslo, Norway; ${ }^{6}$ Centre for Heart Failure Research, Oslo University Hospital, Oslo, Norway; ${ }^{7}$ Department of Clinical Psychology, University of Bergen, Bergen, Norway; ${ }^{8}$ Department of Cardiothoracic Surgery, Oslo University Hospital Rikshospitalet, Oslo, Norway; ${ }^{9}$ Department of Psychiatry, University of Pittsburgh School of Medicine, Pittsburgh, Pennsylvania, USA; ${ }^{10}$ Department of Psychology, University of Oslo, Oslo, Norway; ${ }^{11}$ Department of Research and Education, Oslo University Hospital Rikshospitalet, Oslo, Norway 
Corresponding author: Britta S. Bürker, MD, c/o S. Andersson, Department of Psychology, University of Oslo, Pb. 1094 Blindern, 0317 Oslo, Norway. Telephone: +47-22845928. Fax: +4722845001. E-mail address: $\underline{\text { b.s.buerker@medisin.uio.no }}$

Word count: 6153 - Manuscript includes 4 tables and 1 figure, plus 1 supplementary table (i.e., Supplemental Digital Content)

Running head: Depression and mortality after HTx

Conflicts of interest: E. Gude has given lectures for Novartis and Heartware. A.E. Fiane is consultant for Heartware. All other authors declare no conflicts of interest.

Source of funding: B.S. Bürker received an unrestricted research grant from Throne Holst to U.F. Malt's research group. 


\begin{abstract}
Objective: Current understanding of the prognostic impact of depression on mortality after heart transplantation (HTx) is limited. We examined whether depression after HTx is a predictor of mortality during extended follow-up. Subsequently, we explored whether different symptom dimensions of depression could be identified, and whether they were differentially associated with mortality.
\end{abstract}

Methods: Survival analyses were performed in a sample of $141 \mathrm{HTx}$ recipients assessed for depression, measured by self-report of depressive symptoms (Beck Depression Inventory version 1A (BDI-1A)), at median 5.0 years after HTx, and followed thereafter for survival status for up to 18.6 years. We used uni- and multivariate Cox proportional hazard models to examine the association of clinically significant depression (BDI-1A total score $\geq 10$ ), as well as the cognitive-affective and the somatic subscales of the BDI-1A (resulting from principal component analysis) with mortality. In the multivariate analyses, we adjusted for relevant sociodemographic and clinical variables.

Results: Clinically significant depression was a significant predictor of mortality (hazard ratio (HR): 2.088; 95\% confidence interval (95\% CI): 1.366-3.192; $\mathrm{p}=.001)$. Clinically significant depression also was an independent predictor of mortality in the multivariate analysis (HR: 1.982; 95\% CI: $1.220-3.217 ; \mathrm{p}=.006$ ). The somatic subscale, but not the cognitive-affective subscale, was significantly associated with increased mortality in univariate analyses, while neither of the two subscales was an independent predictor of mortality in the multivariate analysis. 
Conclusions: Depression measured by self-report after HTx is associated with increased mortality during extended follow-up. Clinical utility and predictive validity of specific depression components require further study.

$\underline{\text { Key words: depressive disorder; depression; heart transplantation; mortality; survival }}$ Acronyms: $\mathrm{ACS}=$ acute coronary syndrome; BDI-1A = Beck Depression Inventory - version $1 \mathrm{~A} ; \mathrm{BMI}=$ body mass index $; \mathrm{CAD}=$ coronary artery disease CAV = cardiac allograft vasculopathy; $\mathrm{eGFR}=$ estimated glomerular filtration rate; $\mathrm{HR}=$ hazard ratio; $\mathrm{HTx}=$ heart transplantation; IQR = interquartile range; $\mathrm{OUH}=$ Oslo University Hospital; $\mathrm{PCA}=$ principal component analysis; $\mathrm{SD}=$ standard deviation; $95 \% \mathrm{CI}=95 \%$ confidence interval 


\section{Introduction}

Improvements in immunosuppressive therapy and management of somatic complications after heart transplantation (HTx) have led to improved survival (1). To enhance outcomes further, research has increasingly focused on potentially related psychosocial issues $(2,3)$, including posttransplant depression.

Although data on the association of depression with increased mortality after HTx seem robust in the medium term (i.e., median observation time of 5.4 years across studies in a meta-analysis (4)) (4-6), knowledge is limited about depression's long-term effects on mortality (7).

Furthermore, several aspects of the interplay between depression and prognosis remain unknown or poorly understood. In the setting of coronary artery disease (CAD), an integrative model of the complex interplay between depression and prognosis has been proposed (8). Within this framework, it is hypothesized that acute depression after acute coronary syndrome (ACS) reflects the psychological impact of this event (8). Persistent/recurrent depression is hypothesized to act as an indirect causal factor in the progression of CAD via behavioural pathways such as nonadherence to medication, poor diet, and limited physical activity (8). The model is based partly on findings of cognitive-affective and somatic symptom dimensions of depression in depressed CAD and ACS patients, with the somatic dimension hypothesized to be associated with less favourable prognosis (8). A meta-analysis has confirmed the stronger and more consistent association of the somatic (e.g., work difficulty, insomnia, fatigability) than the cognitiveaffective (e.g., sense of failure, guilt, self-dislike) symptom dimension with cardiovascular prognosis (including all-cause mortality), based on 13 prospective longitudinal studies in patients with heart disease (9); however we lack comparable data on HTx samples. 
Several sociodemographic and clinical characteristics are associated with increased mortality after HTx. Studies focusing on the interplay between depression and prognosis should therefore include these variables as covariates. Recipient age (1), recipient sex (1), reason for HTx (10), donor age (1), and allograft ischemic time (1) have been directly associated with increased mortality after HTx. Hypertension, hyperlipidemia, renal dysfunction, diabetes, and cardiac allograft vasculopathy (CAV) are important morbidities after HTx, with renal dysfunction and CAV being among the most important contributors to mortality (1). Posttransplant smoking is associated with increased mortality in solid organ transplant recipients, including HTx recipients (11). Regarding body mass index (BMI), data from samples of HTx recipients are somewhat conflicting $(10,12,13)$. BMI should nevertheless be included as covariate in survival analyses because BMI values in the range indicating overweight and obesity are associated with increased mortality in never-smokers without chronic diseases (14).

In this study, we aimed to extend existing knowledge about the prognostic impact of depression after HTx on mortality. To this end, we examined whether depression, measured by self-report of depressive symptoms, at a median of 5.0 years (interquartile range (IQR): 2.1-8.4) after HTx predicted subsequent mortality during extended follow-up (i.e., up to 18.6 years). In subsequent analyses, we explored whether cognitive-affective and somatic symptom dimensions of depression could be identified in our sample of HTx recipients and, in that case, whether these two symptom dimensions were differentially associated with mortality. In multivariate analyses, we adjusted for relevant sociodemographic and clinical variables. 


\section{Methods}

Study sample

In Norway, all HTx surgery is performed at the national transplant centre located at Oslo University Hospital (OUH). Selection of HTx candidates follows international guidelines (15). After the first year, HTx recipients return annually to OUH for their follow-up assessments. Of 220 HTx recipients who returned to OUH for their annual follow-up between 1998 and 2000, 147 were included in a study focused on psychiatric symptoms and quality of life. Cross-sectional data (16), longitudinal data on the association between depressive symptoms and mortality during a mean follow-up of 6 years (5), and longitudinal data on the association between self-reported physical function and mortality during a mean follow-up of 10 years (17) have been reported earlier. For the present study, end of follow-up for survival status was June 16, 2017. Of the 147 included HTx recipients from the original cohort, 6 were excluded from the current analyses because they had insufficient data for calculating a total score of the Beck Depression Inventory version 1A (BDI-1A) (18). Thus, we present data on 141 participants. By June 16, 2017, 100 of these 141 HTx recipients had died, 2 were re-transplanted, and 39 were still alive with the same graft (i.e., alive and not re-transplanted). Median follow-up interval from inclusion in the main study and end of follow-up for the present study was 10.7 years (IQR: 5.8-17.6; mean: 10.9; standard deviation (SD): 5.8). Maximum of follow-up was 18.6 years. Median time interval between HTx and inclusion into the main study (i.e., self-report of depressive symptoms) was 5.0 years (IQR: 2.1-8.4; mean: 5.6; SD: 3.9).

\section{Procedures}

The present study is a secondary analysis. To this end, the database of the main study was updated regarding survival status and cause of death through June 16, 2017. The regional 
committee for medical and health research ethics had approved the present secondary analysis as part of the approval of the main study.

\section{Measures}

\section{Self-report of depressive symptoms}

Depressive symptoms were measured by self-report at time of inclusion (i.e., 1998-2000), at a median of 5.0 years (IQR: 2.1-8.4) after HTx, with the BDI-1A (18). The BDI-1A consists of 21 items, rated from 0 to 3 in terms of intensity (19). The total score is the sum of the scores of the single items (range: 0-63). A Cronbach's alpha of .862 in the present sample indicates good internal consistency for the total score of the BDI-1A. Standard cut-off points to identify severity of depressive symptoms have been determined by the developers of the scale (19). A total score of 10 or higher indicates clinically significant depression (19); a total score between 10 and 18 indicates mild depression and a total score of 19 or higher indicates moderate or severe depression (19). A BDI-1A total score $\geq 10$ resulted in a sensitivity of $81.8 \%$ and a specificity of $78.7 \%$ to detect major depression in a sample of $199 \mathrm{CAD}$ patients (20).

Sociodemographic and clinical characteristics

Sociodemographic and clinical characteristics from time of HTx and time of inclusion were analysed to describe the sample, including the covariates in the multivariate survival analyses (see below). Specifically, we report recipient age at time of inclusion (in years), recipient sex, time between HTx and inclusion (in years), reason for HTx, donor age (in years), cold ischemic time (in minutes), renal function at time of inclusion, presence of CAV at time of inclusion, smoking status at time of inclusion (yes/no), and BMI at time of inclusion (in $\mathrm{kg} / \mathrm{m}^{2}$ ). Reason for HTx was classified into three categories: non-ischemic cardiomyopathy (defined according to the American Heart Association (21)), ischemic cardiomyopathy, or other. Renal function was 
measured by means of estimated glomerular filtration rate (eGFR) $(5,22)$, and renal dysfunction defined as eGFR $<60 \mathrm{ml} / \mathrm{min} / 1.73 \mathrm{~m}^{2}$. CAV was defined as luminal narrowing in one or more of the main arteries based on the presence of any of the following: any degree of stenosis, distal tapering/pruning, or loss of tertiary vessels (5). Smoking status was based on self-report, nurses' report, or hospital medical records (5). Cause of death is reported as part of the description of the sample.

\section{Statistical analysis}

Descriptive data are presented as frequencies and proportions or means and SD, as appropriate.

Because mortality was the event of interest, re-transplanted participants were censored at the time of re-HTx in the survival analyses. Observation time started at time of inclusion in the main study (i.e., 1998-2000) and was measured in days until death or censoring (i.e., end of follow-up or reHTx) as appropriate. No participant was lost to follow-up regarding survival status.

We used the Kaplan-Meier method to calculate survival curves and tested for differences in survival with the log-rank test between those with and without depression (i.e., BDI-1A total score $\geq 10$ and $<10$ ) at time of inclusion.

Predictive validity of depression (i.e., BDI-1A total score $\geq 10$ ), as well as the relevant covariates (see below) on mortality, was assessed with univariate Cox proportional hazard models. For the categorical variables, the category associated with lower risk for mortality was chosen as the reference category. Furthermore, we calculated a multivariate Cox proportional hazard model, considering depression and the covariates. For the presented Cox proportional hazard models, hazard ratios (HRs), 95\% confidence intervals (95\% CIs), and corresponding p-values are 
reported. The multivariate model is based on data for all participants with complete datasets, thus incorporating data for 136 out of 141 participants.

For the reasons outlined in the introduction, the following variables were included as covariates in the multivariate analysis: recipient age at time of inclusion, recipient sex, reason for HTx, donor age, duration of cold ischemic time, presence of renal dysfunction at time of inclusion, presence of CAV at time of inclusion, smoking status at time of inclusion, and BMI at time of inclusion. In addition to these variables, we included time between HTx and inclusion as covariate because this time interval varied considerably across included participants (median: 5.0 years; IQR: 2.1-8.4).

Based on existing literature, indicating that only clinically significant depression (according to diagnostic criteria or scores above threshold for caseness on self-report scales) is consistently associated with increased mortality (4), and aiming at highest possible applicability of our results to the clinic, we used the BDI-1A as dichotomous variable (i.e., BDI-1A total score $\geq 10$ or $<10$ ) in our primary analyses. However, to explore the possibility of a dose-response relationship, we also conducted the analyses with the BDI-1A total score as continuous variable.

To explore whether cognitive-affective and somatic symptom dimensions of depression could be identified in our sample of HTx recipients, we conducted principal component analysis (PCA) on the items of the BDI-1A and pre-specified a solution with two components, using oblique rotation (Oblimin with Kaiser Normalization). Prior to performance of PCA, the suitability of the data for this statistical procedure was assessed. Inspection of the correlation matrix, as well as a KaiserMeyer-Olkin value of .803 and the result of the Bartlett's test of sphericity $(\mathrm{p}<.001)$, indicated suitability (23). To assess whether the resulting two components were differentially associated with mortality, we created subscales of the BDI-1A, namely a cognitive-affective and a somatic 
subscale. To this end, we assigned the 21 single items of the BDI-1A to either the cognitiveaffective or the somatic subscale, based on the loadings from the pattern matrix, and calculated sum scores for the subscales, comparable to the total score. As a measure of internal consistency, we calculated Cronbach's alpha for these two subscales.

In parallel with the abovementioned, we calculated uni- and multivariate Cox proportional hazard models with the resulting two subscales of the BDI-1A. In the multivariate Cox proportional hazard model, we considered the two subscales of the BDI-1A simultaneously. The subscales of the BDI-1A were treated as continuous variables because no cut-offs have been established.

Level of significance was set to $\mathrm{p} \leq .050$ in all analyses.

Statistical analyses were performed with IBM SPSS Statistics software (IBM Corporation, Armonk, NY, USA).

\section{Results}

\section{Sample characteristics}

At time of inclusion, mean age was 53.5 years, $20.6 \%$ were female, and $38.3 \%$ had been transplanted for non-ischemic cardiomyopathy. Of 141 participants, $36(25.5 \%)$ had a BDI-1A total score of 10 or higher, indicative of clinically significant depression. Of these 36 participants, 24 had a BDI-1A total score between 10 and <19 (i.e., indicative of mild depression), and 12 had a BDI-1A total score of 19 or higher (i.e., indicative of moderate or severe depression). More details concerning sociodemographic and clinical characteristics are shown in Table 1. During follow-up, 100 (70.9\%) of the 141 participants died. Cancer (30.0\%), CAV (17.0\%), and infection $(12.0 \%)$ were the most frequently registered causes of death, while sudden death (7.0\%), renal dysfunction (5.0\%), acute rejection (4.0\%), and myocardial infarction (1.0\%) were 
less frequently registered. Other miscellaneous causes of death were listed for $21.0 \%$. Cause of death was unknown for 3.0\%. No participant received left ventricular assist device as rescue therapy in our cohort.

\section{Survival analyses}

Figure 1 illustrates the course of survival for participants with and without clinically significant depression (i.e., BDI-1A total score $\geq 10$ or $<10$ ). Log-rank test indicated increased mortality for those with clinically significant depression at inclusion compared to those without $\left(\chi^{2}: 12.079\right.$; df: $1 ; \mathrm{p}=.001)$.

Results from the univariate Cox proportional hazard models are shown in Table 2. In these analyses, clinically significant depression (i.e., BDI-1A total score $\geq 10$ ) was a significant predictor of mortality. Clinically significant depression remained an independent predictor of mortality in the multivariate analysis. For more details, including HR and 95\% CI values, see Table 3.

Treating BDI-1A total score as continuous variable resulted in comparable findings. The BDI-1A total score was significantly associated with increased mortality in the univariate Cox proportional hazard model (HR: 1.032; 95\% CI: 1.006-1.058; $\mathrm{p}=.016$ ). It also remained an independent predictor of mortality in the multivariate analysis (HR: 1.032; 95\% CI: 1.002-1.064; $\mathrm{p}=0.039)$.

Cognitive-affective and somatic symptom dimensions of depression and their association with mortality

The two-component solution of the PCA explained $40.6 \%$ of the variance. The components were interrelated ( $\mathrm{r}=.362)$. After Oblimin rotation, items such as self-dislike, sense of failure, self- 
punishment, sadness, and self-accusation loaded highest on component 1, while items such as fatigability, insomnia, loss of libido, and work difficulty loaded highest on component 2. Component 1 was labelled the cognitive-affective and component 2 was labelled the somatic symptom dimension of depression. Based on the pattern matrix (see Table S1 in the Supplemental Digital Content, which depicts the pattern and structure matrix for the PCA with Oblimin rotation of the two-component solution of the BDI-1A items), cognitive-affective and somatic subscales of the BDI-1A were established for the subsequent survival analyses, as outlined earlier. The cognitive-affective subscale consisted of the BDI-1A items 1, 2, 3, 5, 6, 7, 8, $9,10,11,12,13,14,19$, and 20 , while the somatic subscale consisted of the BDI-1A items 4,15 , $16,17,18$, and 21 . Cronbach's alpha for the cognitive-affective subscale was .850 , while it was .700 for the somatic subscale.

In univariate Cox proportional hazard models, the somatic subscale of the BDI-1A was significantly associated with increased mortality (HR: 1.191; 95\% CI: 1.109-1.280; p<.001), while the cognitive-affective subscale of the BDI-1A was not significantly associated with mortality (HR: 1.017; 95\% CI: .979-1.056; $\mathrm{p}=0.40$ ). Neither the cognitive-affective nor the somatic subscale of the BDI-1A was independently associated with increased mortality in the multivariate analysis. More details, including HR and 95\% CI values, are shown in Table 4.

\section{Discussion}

In the present study, we aimed to extend existing knowledge about the prognostic impact of depression after HTx on mortality. Clinically significant depression assessed at a median of 5.0 years after HTx, and defined as a score above threshold on a self-report scale of depressive symptoms (i.e., BDI-1A total score $\geq 10$ ), was associated with increased mortality during 
extended follow-up (i.e., up to 18.6 years), even after adjustment for relevant sociodemographic and clinical variables.

Subsequent exploratory analyses suggested that a cognitive-affective and a somatic symptom dimension of depression might exist in our sample of HTx recipients. While the somatic symptom dimension was associated with mortality in univariate analysis, neither the cognitiveaffective nor the somatic symptom dimension was independently associated with mortality in multivariate analysis.

Our results confirm earlier reports on the association of depression with increased mortality (4-6) after HTx. At the same time, our results extend previous limited knowledge about depression's long-term effects on mortality. Only one earlier report examined the relationship between depression and survival during extended follow-up (i.e., mean follow-up: 7.8 years) (7). Among 107 HTx recipients, assessed with regard to depression by a clinician one to five years after HTx, depression was not associated with mortality, while age at HTx, cancer, and low adherence were (7). The discrepancy in findings might be due to inclusion of different covariates, differences in analytical techniques, and/or different methods for assessing depression. Our results are however, in line with results from a meta-analysis, considering studies with primarily shorter follow-up intervals (4).

Our results also suggest that a dose-response relationship between self-reported depressive symptoms after HTx and mortality might exist. Earlier reports on HTx samples were inconclusive in this regard $(6,24)$. However, existence of a dose-response relationship would be in accordance with data on patients with $\operatorname{CAD}(25,26)$. 
We are not aware of any earlier report concerning different symptom dimensions of depression in HTx recipients. Thus, it is difficult to relate our exploratory results to truly comparable data, having in mind, that HTx recipients differ substantially from all other patients with heart disease (e.g., use of necessary immunosuppressive medication). However, our finding that a cognitiveaffective and a somatic symptom dimension of depression might exist is consistent with data on patients with heart disease (9). However, a differential prognostic impact on mortality, as reported for samples of patients with heart disease (9), could not be demonstrated.

The following aspects need consideration in the interpretation of our main result. First, we defined clinically significant depression based on a score above threshold on a self-report scale of depressive symptoms (i.e., BDI-1A total score $\geq 10$ ). While BDI-1A is an accepted measure and has been widely used in research on depression in somatic disease samples (included heart disease samples) (27), the methodological limitations of BDI-1A's use as measure of clinically significant depression have been discussed in the literature, including the possible inflation of scale scores due to somatic symptoms of the underlying somatic disease (28). In other words, without concurrent clinical diagnostic data, we cannot determine to which extent different factors, such as fatigue, psychiatric comorbidities (e.g., anxiety disorder), and/or somatic symptoms due to underlying somatic disease or somatic comorbidities might have influenced on our participants' self-report of depressive symptoms. Second, the participants were included at a median of 5.0 years after HTx. Thus, the results of our study are not necessarily generalizable to other cohorts of HTx recipients, especially those studied earlier after HTx. Third, numerous factors are associated with mortality after HTx, making it difficult to account for all potentially relevant confounding factors in the same study. Due to the extended follow-up period, we 
focused on HTx specific factors, included HTx specific morbidities. However, there are other variables, which we ideally should have accounted for, such as socioeconomic status and a global measure of comorbidity (such as the Charlson comorbidity index). Fourth, depression is a complex syndrome. Several factors, that might be involved in the aetiology of depression or might be a result of depression (and hence mediators of any linkage between depression and mortality), were not assessed in our study. These include biological markers of changes in the hypothalamic-pituitary-adrenal axis (e.g., cortisol) and inflammation (e.g., C-reactive protein), as well as behavioural factors (e.g., physical inactivity, poor adherence to the medical regimen) (4, $8,29,30)$. Especially, the interplay between depressive symptoms/depression and physical function requires further exploration because both impaired self-reported physical health and peak oxygen uptake (an objective marker of cardiopulmonary fitness) have been associated with increased mortality (17). A better understanding of this interplay also would be of substantial interest regarding the hypothesis that persistent/recurrent depression may exert its negative prognostic impact via behavioural pathways (8).

Our study has several additional limitations. First, while we know that no participant was receiving treatment for depression at time of inclusion (5), we have no information about the longitudinal course of the included participants' depressive symptoms and/or whether they received treatment for depression at a later time point. It might seem surprising that no participant was receiving treatment for depression at time of inclusion (i.e., 1998-2000). However, at that time, depression screening was not done routinely in conjunction with annual follow-up assessments and a psychiatrist was only involved upon request. Thus, against the background of the widely accepted notion, that depressed patients not always are recognized as depressed by 
their treating non-psychiatric physicians (31), depressed participants might have remained undetected and untreated. Moreover, repeated longitudinal assessment of depressive symptoms and information about treatment for depression after inclusion would have been of interest because persistent/recurrent depression might be associated with less favourable prognosis than brief episodes of depression $(8,32,33)$. Second, the included participants' self-report of depressive symptoms was gathered at different time points after their HTx (i.e., time between HTx and inclusion/self-report of depressive symptoms varied considerably). However, to account for this limitation time between HTx and inclusion was included as covariate in the multivariate analyses. It is also noteworthy, that the correlation of time between HTx and inclusion and BDI1A total score was small and not statistically significant $(\mathrm{r}=.103 ; \mathrm{p}=.23)$. Third, several limitations pertain to the subsequent exploratory analyses. Even if Cronbach's alpha for the BDI1A cognitive-affective and somatic subscales indicates good to acceptable internal consistency, detailed inspection of the pattern matrix resulting from the two-component solution of the PCA indicates that assignment of some of the items to one of the two subscales is not clear-cut (see Table S1 in the Supplemental Digital Content). However, the pattern in which the single items of the BDI-1A loaded highest on either component 1 (labelled the cognitive-affective symptom dimension of depression) or component 2 (labelled the somatic symptom dimension of depression) was broadly consistent with the results from a meta-analysis on studies in patients with heart disease (9). Thus, even though the two-component solution of the PCA presented here is broadly consistent with results from a meta-analysis on studies in patients with heart disease (9), it does not represent an ideal solution and must be replicated in other samples of HTx recipients before firm conclusions can be drawn. Another limitation concerning the PCA is the relatively small sample size, compromising the generalizability of the results. However, the sample size $(\mathrm{n}=141)$ is above the minimum recommended by some authors (i.e., at least 5 cases 
per analysed item) (23). Furthermore, elevation of scale scores due to symptoms of underlying somatic disease (28) have to be discussed in this context as well. If scores on the resulting somatic subscale of the BDI-1A were elevated due to somatic symptoms, originating from somatic comorbidity in our HTx recipients, lack of adjustment for a global measure of comorbidity in our survival analyses would be problematic. The fact that the somatic subscale of the BDI-1A was associated with increased mortality only in univariate analysis, might support this view. On the other hand, lack of power to detect such an effect in the multivariate analysis must be considered as well. Again, concurrent clinical diagnostic data, including description of clinical subtypes of depression, would have been useful for interpreting the results of our exploratory analyses.

In conclusion, our findings both confirm and extend earlier reports, indicating that clinically significant depression after HTx, defined as score above threshold on a self-report scale of depressive symptoms, is associated with increased mortality during extended follow-up, even after adjustment for relevant sociodemographic and clinical variables. Furthermore, our findings suggest that different symptom dimensions of depression may exist. Their clinical utility and prognostic validity remains, however, unsettled and should be studied further in order to increase our understanding of the complex interplay between depression and prognosis after HTx. Increased understanding of this interplay could pave the way for better (i.e., more specific) strategies for clinical interventions.

Adequately powered studies are needed to assess if successful treatment for depression (by means of both psychotropic medications and/or psychotherapeutic interventions as appropriate) improves survival among HTx recipients. HTx recipients who screen positive for possible 
clinically significant depression during routine follow-up should in any case be referred to specialized diagnostics and treatment because depression negatively affects quality of life and function in daily life.

\section{Authors' contributions}

All authors contributed to the interpretation of data and revised the manuscript critically. All authors approved the final and submitted version. The specific author contributions were as follows: B.S. Bürker: updated the database, analysed the data, and drafted the manuscript. L. Gullestad: participated in designing the main study and supported the update of the database. O.E. Havik: participated in designing the main study. A. Relbo Authen and I. Grov: participated in collecting data for the main study and supported the update of the database.

\section{Conflicts of interest}

E. Gude has given lectures for Novartis and Heartware. A.E. Fiane is consultant for Heartware. All other authors declare no conflicts of interest.

\section{Source of funding}

B.S. Bürker received an unrestricted research grant from Throne Holst to U.F. Malt's research group.

\section{Supplemental Digital Content}

Table S1. Pattern and structure matrix for principal component analysis with Oblimin rotation of the two-component solution of the BDI-1A items (Bürker Table S1.pdf) 


\section{References}

1. Lund LH, Khush KK, Cherikh WS, Goldfarb S, Kucheryavaya AY, Levvey BJ, Meiser B, Rossano JW, Chambers DC, Yusen RD, Stehlik J. The Registry of the International Society for Heart and Lung Transplantation: Thirty-fourth Adult Heart Transplantation Report-2017; Focus Theme: Allograft ischemic time. J Heart Lung Transplant. 2017;36:1037-46.

2. Cupples S, Dew MA, Grady KL, De Geest S, Dobbels F, Lanuza D, Paris W. Report of the Psychosocial Outcomes Workgroup of the Nursing and Social Sciences Council of the International Society for Heart and Lung Transplantation: present status of research on psychosocial outcomes in cardiothoracic transplantation: review and recommendations for the field. J Heart Lung Transplant. 2006;25:716-25.

3. Maldonado JR, Sher Y, Lolak S, Swendsen H, Skibola D, Neri E, David EE, Sullivan C, Standridge K. The Stanford Integrated Psychosocial Assessment for Transplantation: A Prospective Study of Medical and Psychosocial Outcomes. Psychosom Med. 2015;77:1018-30. 4. Dew MA, Rosenberger EM, Myaskovsky L, DiMartini AF, DeVito Dabbs AJ, Posluszny DM, Steel J, Switzer GE, Shellmer DA, Greenhouse JB. Depression and Anxiety as Risk Factors for Morbidity and Mortality After Organ Transplantation: A Systematic Review and MetaAnalysis. Transplantation. 2015;100:988-1003.

5. Havik OE, Sivertsen B, Relbo A, Hellesvik M, Grov I, Geiran O, Andreassen AK, Simonsen S, Gullestad L. Depressive symptoms and all-cause mortality after heart transplantation. Transplantation. 2007;84:97-103.

6. Spaderna H, Zittermann A, Reichenspurner H, Ziegler C, Smits J, Weidner G. Role of Depression and Social Isolation at Time of Waitlisting for Survival 8 Years After Heart Transplantation. Journal of the American Heart Association. 2017;6. 
7. Favaro A, Gerosa G, Caforio AL, Volpe B, Rupolo G, Zarneri D, Boscolo S, Pavan C, Tenconi E, d'Agostino C, Moz M, Torregrossa G, Feltrin G, Gambino A, Santonastaso P. Posttraumatic stress disorder and depression in heart transplantation recipients: the relationship with outcome and adherence to medical treatment. Gen Hosp Psychiatry. 2011;33:1-7.

8. Ormel J, de Jonge P. Unipolar depression and the progression of coronary artery disease: toward an integrative model. Psychother Psychosom. 2011;80:264-74.

9. de Miranda Azevedo R, Roest AM, Hoen PW, de Jonge P. Cognitive/affective and somatic/affective symptoms of depression in patients with heart disease and their association with cardiovascular prognosis: a meta-analysis. Psychol Med. 2014;44:2689-703.

10. Lund LH, Edwards LB, Dipchand AI, Goldfarb S, Kucheryavaya AY, Levvey BJ, Meiser B, Rossano JW, Yusen RD, Stehlik J. The Registry of the International Society for Heart and Lung Transplantation: Thirty-third Adult Heart Transplantation Report-2016; Focus Theme: Primary Diagnostic Indications for Transplant. J Heart Lung Transplant. 2016;35:1158-69.

11. Duerinckx N, Burkhalter H, Engberg SJ, Kirsch M, Klem ML, Sereika SM, De Simone P, De Geest S, Dobbels F. Correlates and Outcomes of Posttransplant Smoking in Solid Organ Transplant Recipients: A Systematic Literature Review and Meta-Analysis. Transplantation. 2016;100:2252-63.

12. Jalowiec A, Grady KL, White-Williams C. Clinical outcomes in overweight heart transplant recipients. Heart Lung. 2016;45:298-304.

13. Weber DJ, Hashmi ZA, Gracon AS, Hellman YM, Patel AJ, Wozniak TC, Wang IW. Recipient body mass index and age interact to impact survival after heart transplantation. Clin Transplant. 2014;28:1279-86.

14. Di Angelantonio E, Bhupathiraju Sh N, Wormser D, Gao P, Kaptoge S, Berrington de Gonzalez A, Cairns BJ, Huxley R, Jackson Ch L, Joshy G, Lewington S, Manson JE, Murphy N, 
Patel AV, Samet JM, Woodward M, Zheng W, Zhou M, Bansal N, Barricarte A, Carter B, Cerhan JR, Smith GD, Fang X, Franco OH, Green J, Halsey J, Hildebrand JS, Jung KJ, Korda RJ, McLerran DF, Moore SC, O'Keeffe LM, Paige E, Ramond A, Reeves GK, Rolland B, Sacerdote C, Sattar N, Sofianopoulou E, Stevens J, Thun M, Ueshima H, Yang L, Yun YD, Willeit P, Banks E, Beral V, Chen Z, Gapstur SM, Gunter MJ, Hartge P, Jee SH, Lam TH, Peto R, Potter JD, Willett WC, Thompson SG, Danesh J, Hu FB. Body-mass index and all-cause mortality: individual-participant-data meta-analysis of 239 prospective studies in four continents. Lancet. 2016;388:776-86.

15. ISHLT. ISHLT standards statements, guidelines, and consensus documents. Available from: http://ishlt.org/guidelines/standardsStatements.asp.

16. Sivertsen B, Relbo A, Gullestad L, Hellesvik M, Grov I, Andreassen A, Simonsen S, Geiran O, Havik OE. [Self-assessed health and psychological symptoms after heart transplantation]. Tidsskr Nor Laegeforen. 2007;127:3198-201.

17. Yardley M, Havik OE, Grov I, Relbo A, Gullestad L, Nytroen K. Peak oxygen uptake and self-reported physical health are strong predictors of long-term survival after heart transplantation. Clin Transplant. 2016;30:161-9.

18. Beck AT, Rush AJ, Shaw BF, Emery G. Cognitive therapy of depression. Chichester: John Wiley \& Sons Ltd.; 1979.

19. Beck AT, Steer RA, Carbin MG. Psychometric properties of the Beck Depression Inventory: Twenty-five years of evaluation. Clin Psychol Rev. 1988;8:77-100.

20. Strik JJ, Honig A, Lousberg R, Denollet J. Sensitivity and specificity of observer and selfreport questionnaires in major and minor depression following myocardial infarction. Psychosomatics. 2001;42:423-8. 
21. AHA. What Is Cardiomyopathy in Adults? 2016; Available from:

http://www.heart.org/HEARTORG/Conditions/More/Cardiomyopathy/What-Is-Cardiomyopathy-

\section{in-Adults_UCM_444168_Article.jsp.}

22. Hillege HL, Nitsch D, Pfeffer MA, Swedberg K, McMurray JJ, Yusuf S, Granger CB, Michelson EL, Ostergren J, Cornel JH, de Zeeuw D, Pocock S, van Veldhuisen DJ. Renal function as a predictor of outcome in a broad spectrum of patients with heart failure. Circulation. 2006;113:671-8.

23. Pallant J. SPSS Survival Manual: A step by step guide to data analysis using SPSS. 4th edition. Crows Nest: Allen \& Unwin; 2011.

24. Farmer SA, Grady KL, Wang E, McGee EC, Jr., Cotts WG, McCarthy PM. Demographic, psychosocial, and behavioral factors associated with survival after heart transplantation. Ann Thorac Surg. 2013;95:876-83.

25. Bush DE, Ziegelstein RC, Tayback M, Richter D, Stevens S, Zahalsky H, Fauerbach JA. Even minimal symptoms of depression increase mortality risk after acute myocardial infarction. Am J Cardiol. 2001;88:337-41.

26. Lespérance F, Frasure-Smith N, Talajic M, Bourassa MG. Five-year risk of cardiac mortality in relation to initial severity and one-year changes in depression symptoms after myocardial infarction. Circulation. 2002;105:1049-53.

27. Davidson KW, Kupfer DJ, Bigger JT, Califf RM, Carney RM, Coyne JC, Czajkowski SM, Frank E, Frasure-Smith N, Freedland KE, Froelicher ES, Glassman AH, Katon WJ, Kaufmann PG, Kessler RC, Kraemer HC, Krishnan KR, Lesperance F, Rieckmann N, Sheps DS, Suls JM. Assessment and treatment of depression in patients with cardiovascular disease:

National Heart, Lung, and Blood Institute Working Group Report. Psychosom Med. 2006;68:645-50. 
28. Delisle VC, Beck AT, Ziegelstein RC, Thombs BD. Symptoms of heart disease or its treatment may increase Beck Depression Inventory Scores in hospitalized post-myocardial infarction patients. J Psychosom Res. 2012;73:157-62.

29. Carney RM, Freedland KE, Steinmeyer B, Rubin EH, Mann DL, Rich MW. Cardiac Risk Markers and Response to Depression Treatment in Patients With Coronary Heart Disease. Psychosom Med. 2016;78:49-59.

30. Kop WJ. Role of psychological factors in the clinical course of heart transplant patients. J Heart Lung Transplant. 2010;29:257-60.

31. Cepoiu M, McCusker J, Cole MG, Sewitch M, Belzile E, Ciampi A. Recognition of depression by non-psychiatric physicians--a systematic literature review and meta-analysis. J Gen Intern Med. 2008;23:25-36.

32. Carney RM, Freedland KE, Steinmeyer BC, Rubin EH, Rich MW. Residual Symptoms After Treatment for Depression in Patients With Coronary Heart Disease. Psychosom Med. 2018;80:385-92.

33. Freedland KE, Hesseler MJ, Carney RM, Steinmeyer BC, Skala JA, Davila-Roman VG, Rich MW. Major Depression and Long-Term Survival of Patients With Heart Failure. Psychosom Med. 2016;78:896-903. 
Table 1. Sociodemographic and clinical characteristics $(n=141)$

Recipient age $^{\text {a }}$ (years), mean (SD)

Recipient sex, female/male (\% female)

Time between HTx and inclusion (years), mean (SD)

Reason for HTx, n (\%)

Non-ischemic cardiomyopathy

Ischemic cardiomyopathy

Other

Donor age (years), mean (SD) [n=138]

Cold ischemic time (min), mean (SD) [n=138]

$\operatorname{eGFR}^{\mathrm{a}, \mathrm{b}}\left(\mathrm{ml} / \mathrm{min} / 1.73 \mathrm{~m}^{2}\right)$, mean (SD) [n=137]

$\mathrm{CAV}^{\mathrm{a}}, \mathbf{n}(\%)$

Smoking status ${ }^{\text {a }}$, yes/no (\% yes)

$\operatorname{BMI}^{\mathrm{a}}\left(\mathrm{kg} / \mathrm{m}^{2}\right)$, mean $(\mathrm{SD})[\mathrm{n}=140]$

BDI-1A total score ${ }^{\mathrm{a}, \mathrm{c}}$, mean (SD)

$53.5 \quad(12.5)$

$29 / 112 \quad(20.6)$

$5.6 \quad(3.9)$

$54 \quad(38.3)$

$73 \quad(51.8)$

$14 \quad(9.9)$

$30.9 \quad(11.5)$

$136 \quad(65)$

$60.7 \quad(17.6)$

$33 \quad(23.4)$

$31 / 110 \quad(22.0)$

$26.2 \quad(4.2)$

$7.4 \quad(6.7)$ 
BDI-1A = Beck Depression Inventory - version 1A; BMI = body mass index; CAV = cardiac allograft vasculopathy; eGFR = estimated glomerular filtration rate; $\mathrm{HTx}=$ heart transplantation; $\mathrm{SD}=$ standard deviation.

${ }^{a}$ At time of inclusion. ${ }^{b} 50.4 \%$ had an eGFR $<60 \mathrm{ml} / \mathrm{min} / 1.73 \mathrm{~m}^{2} .{ }^{\mathrm{c}} 25.5 \%$ had a BDI-1A total score $\geq 10$. 
Table 2. Univariate Cox proportional hazard models ( $\mathrm{n}=141)$

\begin{tabular}{|c|c|c|c|c|c|}
\hline & Reference category (categorical & HR & $95 \%$ & CI & $\mathbf{p}$ \\
\hline Depression $^{\mathbf{a}, \mathrm{b}}$ & No depression & 2.088 & 1.366 & 3.192 & .001 \\
\hline Recipient age $^{\text {a }}$ (years) & & 1.074 & 1.049 & 1.099 & $<.001$ \\
\hline Recipient sex & Female & 1.108 & .672 & 1.826 & .70 \\
\hline Reason for HTx & Non-ischemic cardiomyopathy & & & & $<.001$ \\
\hline Ischemic cardiomyopathy & & 2.793 & 1.766 & 4.417 & $<.001$ \\
\hline Other & & 1.930 & .954 & 3.903 & .067 \\
\hline Donor age (years) $[n=138]$ & & 1.001 & .983 & 1.018 & .94 \\
\hline Cold ischemic time $(\min )[n=138]$ & & 1.001 & .998 & 1.004 & .55 \\
\hline Renal dysfunction $^{\mathrm{a}, \mathrm{c}}[\mathrm{n}=137]$ & No renal dysfunction & 2.529 & 1.673 & 3.824 & $<.001$ \\
\hline $\mathbf{C A V}^{\mathbf{a}}$ & No CAV & 3.357 & 2.154 & 5.233 & $<.001$ \\
\hline Smoking status ${ }^{\mathrm{a}, \mathrm{d}}$ & No smoking & 1.413 & .892 & 2.237 & .14 \\
\hline $\operatorname{BMI}^{\mathrm{a}}\left(\mathrm{kg} / \mathrm{m}^{2}\right)[\mathrm{n}=140]$ & & 1.095 & 1.051 & 1.141 & $<.001$ \\
\hline
\end{tabular}




\section{Time between HTx and inclusion}

(years)

BDI-1A = Beck Depression Inventory - version 1A; BMI = body mass index; CAV = cardiac allograft vasculopathy; eGFR =

estimated glomerular filtration rate; $\mathrm{HR}=$ hazard ratio; $\mathrm{HTx}=$ heart transplantation; $95 \% \mathrm{CI}=95 \%$ confidence interval.

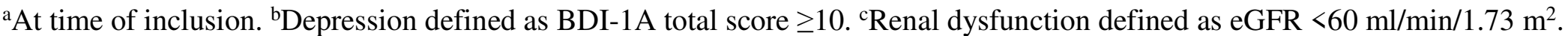

${ }^{\mathrm{d}}$ Yes or no. 
Table 3. Multivariate Cox proportional hazard model - depression $(n=136)$

\begin{tabular}{|c|c|c|c|c|c|}
\hline & Reference category (categorical variables) & HR & \multicolumn{2}{|c|}{$95 \% \mathrm{CI}$} & $\mathbf{p}$ \\
\hline Depression $^{\text {a,b }}$ & No depression & 1.982 & 1.220 & 3.217 & .006 \\
\hline Recipient age $^{\text {a }}$ (years) & & 1.057 & 1.026 & 1.088 & $<.001$ \\
\hline Recipient sex & Female & .914 & .492 & 1.700 & .78 \\
\hline Reason for HTx & Non-ischemic cardiomyopathy & & & & .019 \\
\hline Ischemic cardiomyopathy & & 2.061 & 1.198 & 3.546 & .009 \\
\hline Other & & 2.518 & 1.069 & 5.782 & .030 \\
\hline Donor age (years) & & 1.020 & .997 & 1.043 & .097 \\
\hline Cold ischemic time (min) & & 1.000 & .996 & 1.003 & .87 \\
\hline Renal dysfunction ${ }^{\mathrm{a}, \mathrm{c}}$ & No renal dysfunction & 2.036 & 1.279 & 3.241 & .003 \\
\hline CAV $^{\mathbf{a}}$ & No CAV & 2.832 & 1.510 & 5.310 & .001 \\
\hline Smoking status ${ }^{\mathrm{a}, \mathrm{d}}$ & No smoking & 1.040 & .556 & 1.946 & .90 \\
\hline $\operatorname{BMI}^{\mathrm{a}}\left(\mathrm{kg} / \mathrm{m}^{2}\right)$ & & 1.069 & 1.017 & 1.124 & .008 \\
\hline Time between HTx and inclusion (years) & & 1.064 & .993 & 1.139 & .078 \\
\hline
\end{tabular}


BMI = body mass index; CAV = cardiac allograft vasculopathy; eGFR = estimated glomerular filtration rate; HR = hazard ratio;

$\mathrm{HTx}=$ heart transplantation; $95 \% \mathrm{CI}=95 \%$ confidence interval.

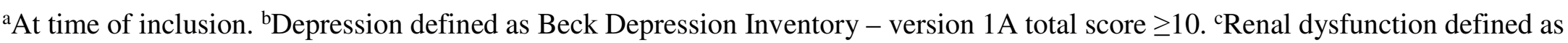
eGFR $<60 \mathrm{ml} / \mathrm{min} / 1.73 \mathrm{~m}^{2} .{ }^{\mathrm{d}}$ Yes or no. 
Table 4. Multivariate Cox proportional hazard model - cognitive-affective and somatic symptom dimension of depression $(\mathrm{n}=136)$

\begin{tabular}{|c|c|c|c|c|c|}
\hline \multirow{2}{*}{ BDI-1A cognitive-affective subscale (resulting } & \multirow{2}{*}{$\begin{array}{l}\text { Reference category (categorical } \\
\text { variables) }\end{array}$} & \multirow{2}{*}{$\begin{array}{l}\text { HR } \\
1.007\end{array}$} & \multicolumn{2}{|c|}{$95 \% \mathrm{CI}$} & \multirow{2}{*}{$\begin{array}{l}\mathbf{p} \\
.081 \\
\end{array}$} \\
\hline & & & .953 & 1.063 & \\
\hline \multicolumn{6}{|l|}{ from $\mathrm{PCA})^{\mathrm{a}}$} \\
\hline BDI-1A somatic subscale (resulting from & & 1.094 & .983 & 1.218 & .10 \\
\hline \multicolumn{6}{|l|}{ PCA $)^{\mathbf{a}}$} \\
\hline Recipient age $^{\text {a }}$ (years) & & 1.055 & 1.024 & 1.086 & $<.001$ \\
\hline Recipient sex & Female & .911 & .488 & 1.702 & .77 \\
\hline Reason for HTx & Non-ischemic cardiomyopathy & & & & .029 \\
\hline Ischemic cardiomyopathy & & 1.937 & 1.116 & 3.362 & .019 \\
\hline Other & & 2.527 & 1.101 & 5.799 & .029 \\
\hline Donor age (years) & & 1.022 & .999 & 1.045 & .066 \\
\hline Cold ischemic time (min) & & 1.000 & .997 & 1.004 & .81 \\
\hline Renal dysfunction ${ }^{\mathrm{a}, \mathrm{b}}$ & No renal dysfunction & 1.926 & 1.198 & 3.095 & .007 \\
\hline
\end{tabular}


CA Va

Smoking status ${ }^{a, c}$

$\operatorname{BMI}^{\mathrm{a}}\left(\mathrm{kg} / \mathrm{m}^{2}\right)$

Time between HTx and inclusion (years)
$2.453 \quad 1.311 \quad 4.592$

.005

No smoking

1.138

.6122 .118

.683

1.078

$1.027 \quad 1.133$

.003

$1.067 \quad .996 \quad 1.142$

.064

BDI-1A = Beck Depression Inventory - version 1A; BMI = body mass index; CAV = cardiac allograft vasculopathy; eGFR =

estimated glomerular filtration rate; $\mathrm{HR}=$ hazard ratio; $\mathrm{HTx}=$ heart transplantation; $\mathrm{PCA}=$ principal component analysis; $95 \% \mathrm{CI}=$ $95 \%$ confidence interval.

${ }^{a}$ At time of inclusion. ${ }^{b}$ Renal dysfunction defined as eGFR $<60 \mathrm{ml} / \mathrm{min} / 1.73 \mathrm{~m}^{2}$. ${ }^{\mathrm{c}}$ Yes or no. 
Figure 1.

Figure 1. Survival curves - Kaplan-Meier method

Depression, defined as BDI-1A total score $\geq 10$.

BDI-1A = Beck Depression Inventory - version 1A. 
